\title{
EDUCAÇÃO AMBIENTAL: ENCONTROS E VERTENTES NA PERSPECTIVA CIVILIZADORA DE NORBERT ELIAS
}

\author{
Roberto Marin Viestel \\ UFOP - UNIMEP, marinviestel@gmail.com
}

\begin{abstract}
RESUMO
O presente artigo é uma interpretação das educações ambientais através da teoria do processo civilizador do sociólogo Norbert Elias. Primeiramente analisamos a questão dos encontros ambientais sob a perspectiva das tensões de poder e do contexto histórico-processual em que foram se formando, sendo o arranjo emocional parte do processo dos encontros; em seguida, destacamos as diversas vertentes das educações ambientais com suas fases e características.
\end{abstract}

\section{INTRODUÇÃO}

\section{Educação Ambiental: encontros, tensão de poder e arranjo emocional}

Ao longo da história da evolução humana os homens encontraram várias maneiras de se relacionar com o ambiente físico, mas, sempre o dominando segundo as suas necessidades. $\mathrm{O}$ comportamento ambiental - entendido enquanto comportamento social - se deu de maneira coletiva e individualizada dentro da história dos povos e dos processos vividos, carregando culturalmente características da estrutura de cada povo; seu destino, portanto, é específico de estruturas específicas. Com o advento do cristianismo, idealizador de habitus pacificadores enquanto filosofia, e o estabelecimento da sociedade de corte, enquanto modelo ocidental de civilização, o comportamento ambiental manifestou-se nas instituições de defesa da natureza, através de regras e leis.

O arranjo emocional dos seres humanos muda com o tempo, o que se revela, por exemplo, nos encontros ambientais. Estes precisaram passar por um período de conhecimento das questões ambientais para a sensibilização da humanidade e chegar, finalmente, a alguma ação. O processo é lento e descontínuo, tendo de enfrentar situações de "descompasso" entre o conhecimento científico e a aceitação moral e comportamental das pessoas. Os primeiros encontros deram-se dentro da realidade européia e formaram uma maneira de lidar com o ambiente que é civilizadora em alguns aspectos, bem como destrutiva em tantos outros. Ninguém discorda, porém, que há um processo de destruição galopante do planeta, mas, para que se chegasse a essa percepção do problema foi necessário que vários encontros acontecessem progressivamente, aliando interesses, desenvolvimento, mudanças comportamentais nas formas de agir. É aí que a questão torna-se mais complicada, pois comportamentos não são alterados repentinamente, dependem de uma série de configurações individuais e maneiras de se apropriar do ambiente físico, seja na forma concreta, seja na forma imaginária. Vemos os encontros ambientais como um estágio do processo civilizador que está em pleno desenvolvimento, sendo difícil mapear todas as suas nuanças. Os conflitos fazem parte do processo, pois harmonização não significa ausência de luta. Essa luta, porém não se apresenta igualmente para todos os povos, pois as formas de ocupação dos espaços serão diferenciadas e envolverão questões bem definidas (como o poder, por exemplo), por outro lado, o elemento comum do processo diz respeito às evidências de civilização encontradas em cada um deles, como por exemplo: o reconhecimento de que hoje habitamos um mesmo planeta, com uma mesma humanidade, com direitos naturais para todas as espécies. Certamente falamos em um avanço de civilização, pois seria impensável falarmos de um só planeta no século XVI ou mesmo 
mesmo no início do século XX. Só recentemente a humanidade conseguiu visualizar-materialmente e metaforicamente - o grande planeta azul solto na imensidão do espaço. Foram necessários séculos para que demônios e deuses "permitissem" tal visão, ainda que estes continuem presentes, porém, adaptáveis em circunstâncias científicas cuja racionalidade é inegável. Se por um lado o pensamento racional é constantemente acusado de agredir o planeta, por outro não é menos verdade que ele aumentou a média de vida da humanidade e proporcionou curas médicas nunca antes imaginadas, entre uma infinidade de avanços.

Os encontros ambientais foram realizados dentro de cada contexto histórico específico de tensões de poder que propiciou grandes orientações à humanidade; eles acabaram fazendo parte de atitudes comportamentais em relação ao ambiente físico. Assim, por exemplo, enquanto na Europa discutia-se, na década de 70, o perigo das armas atômicas, no Brasil, vivíamos um regime militar onde estas armas não tinham um real efeito de perigo iminente, o que não impediu, por outro lado, que um grupo de cientistas no Rio Grande do Sul, liderados por Lutzemberg, alertasse sobre os problemas ambientais. Quer dizer, o elemento comum da humanidade, neste caso, é que tais encontros começam a ter eco nos lugares mais distantes (como o Brasil), seja na comunidade científica, seja na população em geral, e o comportamento será paulatinamente mudado, principalmente quando se vincular questões econômicas, como empréstimos e outras ajudas financeiras. Tal se dá, também, não sem interesses, o que faz com que a tensão de poder determine as regras do jogo, principalmente tratando-se de recursos naturais. Isso não inviabiliza nossa visão de que os encontros se deram - e ainda se dão por um processo longo, em continuidade com transformações comportamentais que vão adquirindo novo formato, influenciando e sendo influenciado.
Os encontros colocaram bases legais para assegurar e garantir novas atitudes dos governos em relação à natureza. Foram decisões políticas. Para que isso pudesse acontecer dependeu de garantias formais dos estados envolvidos no processo. Quando elas não existiram houve perda de prestígio e de poder dos membros envolvidos. O desenvolvimento do comércio, neste sentido, ao contrário do que muitos movimentos ambientalistas afirmam, pode ser visto, também, como o grande impulsionador da unificação de práticas políticas "verdes", ou seja, regulamentadas e manejadas de acordo com padrões ambientais condizentes com o meio físico. Segundo Weber, "a estrutura econômica em geral contribui para determinar as proporções $e$ o modo da expansão política" (WEBER, 1971, p194). O poder econômico das nações mais desenvolvidas ao longo da segunda metade do século XX cobrou padrões de comportamento ambiental das nações mais pobres. O grande reconhecimento paulatino, processual, da destruição causada, em grande parte, foi de responsabilidade destas nações desenvolvidas, o que foi um avanço para a humanidade em termos de uma "meia-culpa", psicologicamente importante para os indivíduos e para a história. Tal salto de visão sobre questões ambientais, comportamentos construídos e condutas secularmente estabelecidas, fez com que o padrão de crescimento econômico mexesse com as decisões políticas e não mais se tratava de exploração colonial ou neocolonial, embora muitos traços permaneçam visíveis, mas de condutas humanas de convivência mútua entre diversas nações, povos, tribos, comunidades e indivíduos. O comportamento ambiental dos indivíduos cresce, também, a reboque destes encontros e das orientações preconizadas, pois, no jogo de poder entre as nações, a responsabilidade para a proteção e o "melhoramento" do meio ambiente - como citado em Estocolmo em 1972 - estabelece graus de comportamento muito bem limitados por decretos, leis, etc, ou seja, coerções que 
modelam atitudes compatíveis com uma natureza saudável, para que todos possam usufruir dela. Vejamos um exemplo empírico de práticas ambientais e jogo de poder entre nações: o caso do Brasil na participação da referida Conferência.

Entre 05 a 16 de junho de 1972, na Suécia, 113 países participam da Conferência da ONU (Organização das Nações Unidas) sobre Meio Ambiente, mais conhecida como Conferência de Estocolmo. Nela se estabelecem 23 princípios gerais para a preservação e melhoria do ambiente humano.

A participação do Brasil levantou a seguinte polêmica na Conferência de Estocolmo: o governo brasileiro acusava os países ricos industrializados em querer limitar os programas de desenvolvimento industrial utilizando como desculpa a questão da poluição. Assim, os nossos representantes pediam poluição e não se importavam em pagar o preço da degradação, desde que gerasse empregos. Uma faixa anunciava a postura brasileira:

Bem-vindos à poluição, estamos abertos para ela. O Brasil é um país que não tem restrições. Temos várias cidades que receberiam de braços abertos a sua poluição, porque o que nós queremos são empregos, são dólares para o nosso desenvolvimento (DIAS, 2000, p36).

A errônea prática ambiental do governo brasileiro mostra que a tensão de poder naquele momento histórico era desenvolvida sobre o tema emprego / desenvolvimento versus destruição ambiental (no caso as diversas formas de poluição). $\mathrm{O}$ que causa estranhamento e vergonha hoje não o causava na década de setenta. O Brasil paulatinamente entrou em práticas ambientais compatíveis com a natureza quando os órgãos internacionais passaram a exigir, contratualmente, cláusulas que incutiam responsabilidade ambiental, que aliassem desenvolvimento com sustentabilidade (sem entrarmos na questão desenvolvimento sustentável / sociedade sustentável). O que está explícito é que o comportamento ambien- tal foi sendo modelado pelos encontros, que pautaram atitudes, valores e concepções do homem sobre si mesmo.

Vários encontros foram realizados, quase como uma sucessão das associações de proteção e conservação que nasceram no século XIX entre os naturalistas e viajantes. Foram necessários séculos de arranjo emocional para que a humanidade passasse a perceber a importância de manejos ajustáveis com práticas de sobrevivência da espécie. $\mathrm{O}$ caso brasileiro mostra que nos desenvolvemos muito rapidamente, pois, em praticamente trinta anos possuímos uma visão, ainda que "distorcida" e confusa em alguns casos (como a prática da educação ambiental, por exemplo), sobre questões ambientais. Possuímos uma das legislações ambientais mais adiantadas do mundo.

Os encontros ambientais são determinados por tensões de poder e momentos históricos específicos, determinados em disputas de prestígio e honra entre as nações. Esse orgulho - fruto do poder - pode se relacionar com poder político de fato - através da demonstração de força - ou, simplesmente, isento de prestígio, agindo-se, portanto, por pura convicção. Grandes comunidades políticas tendem a ser base de pretensões políticas. Não há ingenuidade na política, porém, os encontros, ao determinarem condutas condizentes com as questões ambientais, de acordo com a prática de manejo que se acredita em cada época, produzem nos indivíduos novas reflexões; o indivíduo que é moldado passa a moldar outros indivíduos, agindo em um movimento de reflexão, só que, agora, re-elaborando novos conceitos, incorporando alguns e abandonando outros. $\mathrm{Na}$ "média", como se diz em política pública, há um grau de comportamento e conduta que passa a fazer parte de um padrão ambiental, de uma nova forma de agir em relação à natureza, positivamente civilizadora.

Durante a segunda grande guerra mundial e logo após esta, a humanidade percebeu, a duríssimas penas, duas coisas que mudaram o rumo dos acontecimentos e a 
maneira de olhar para a natureza: a primeira foi o poderio atômico, que produziu a sensação de que temos condições de acabar com o planeta em poucos segundos; a segunda, que a Terra, vista do espaço (corrida espacial), é o grande lar comum de toda a humanidade. Estes dois episódios produziram encontros ambientais com nova forma de interpretar as questões concernentes à natureza. Medo, incerteza, guerra fria, tudo isso fez com que o homem estivesse mais próximo de reflexões individuais mais sentimentais, mais amorosas: o mito da natureza intocada volta à tona! Apesar da criação, na Suíça, em 1947, da União Internacional para a Conservação da Natureza (UICN - um marco), somente em 1972 será produzido o primeiro encontro ambiental. Em 1947 a guerra ainda era muito presente e a tensão do poder estava em reorganizar a Europa pelos países vencedores. Em 1972 a tensão muda e a guerra fria produz uma nova incerteza. Os encontros trazem para agenda pública mundial um tema que veio para ficar, um tema que passa a ser incorporado paulatinamente em todos os cantos do planeta (certamente ganha impulso com as telecomunicações) e novas formas de se comportar são sentidas.

A associação de ambientalismo e prática educativa, ou seja, educação ambiental tem sua origem com as sociedades de proteção e conservação, ainda no século XIX, porém, mais ou menos entendida como hoje, possui sua história bem recente, como, por exemplo, com o aparecimento da expressão estudos ambientais (environmental studies) usada por profissionais da educação na Grã-Bretanha, em 1945. Posteriormente, também, na GrãBretanha, em março de 1965, utiliza-se a expressão educação ambiental (environmental education), como uma parte da educação, deixando de ser utilizada apenas como conservação ou ecologia aplicada (DIAS, 2000, p. 33). Em 1972, em Estocolmo, na Conferência da ONU para o Meio Ambiente, o princípio 19 utiliza o termo “educação em questões ambientais", bem como orienta em assentar bases de informação para condutas responsáveis dos indivíduos, empresas e comunidades, inspirados em responsabilidade para a proteção.

Pela primeira vez foi reconhecido que a 'educação em questões ambientais' (Educação Ambiental, portanto) é essencial para ajudar a solucionar a crise ambiental internacional, reordenando as necessidades básicas de sobrevivência na Terra. Quer dizer, fala-se de uma "conduta responsável dos indivíduos, das empresas e das comunidades", ou seja, um comportamento civilizado, uma exigência de uma ética que revela muito mais do que sobrevivência pura e simplesmente, revela o conteúdo de uma civilização que se reconhece enquanto espécie humana e que, também, reconhece as outras espécies, não-humanas, com o mesmo estatuto de direito à vida. Um código de conduta, de comportamento em relação ao ambiente, indica o início de novos elementos sociais de interdependência entre os indivíduos.

Em 1975 é promovido pela Unesco o encontro de Belgrado. Desta vez é um Encontro de Educação Ambiental que reúne 65 países e estabelece os princípios gerais para um programa internacional de Educação Ambiental, surge o documento conhecido como a Carta de Belgrado. Concomitante ao encontro ocorre reuniões em todos os continentes, excetuando-se a Oceania. A Carta:

... preconizava uma nova ética planetária para promover a erradicação da pobreza, analfabetismo, fome, poluição, exploração e dominação humanas. Censurava o desenvolvimento de uma nação às custas de outra, buscando-se um consenso internacional. Surgiu também a criação de um Programa Mundial em Educação Ambiental (PEDRINI, 1998, p26).

A Carta de Belgrado reconhece as desigualdades entre os países ricos e pobres, e aponta a crescente deterioração do ambiente 
físico. Vejamos um trecho da mesma:

Nossa geração tem testemunhado um crescimento econômico e um progresso tecnológico sem precedentes, os quais, ao tempo em que trouxeram beneficios para muitas pessoas, produziram também sérias conseqüências ambientais e sociais. As desigualdades entre pobres e ricos, nos países e entre países, estão crescendo, e há evidências de crescente deterioração do ambiente físico, numa escala mundial. Essas condições, embora primariamente causadas por um número relativamente pequeno de países, afetam toda a humanidade. (Retirado do sítio do Ministério do Meio Ambiente / Brasil; ver também o sítio Universidade Livre do Meio Ambiente,

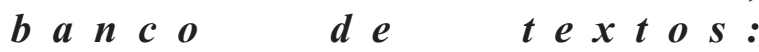
www.bsi.com.br/unilivre/default.htm).

O grande marco deu-se em 1977, quando da $\mathrm{I}^{\mathrm{a}}$ Conferência Intergovernamental sobre Educação Ambiental organizado pela Unesco, mais conhecida como Conferência de Tbilisi. Como resultado a Unesco produz, em 1980, um documento com as finalidades e características da Educação Ambiental, bem como as premissas e os princípios de incorporação da Educação Ambiental aos Programas de Educação. Os pontos gerais das premissas e princípios apontam na direção de que a Educação Ambiental deve se basear na tecnologia e na ciência a fim de construir a adequada compreensão e consciência dos problemas ambientais, o que geraria uma mudança de conduta para com o planeta.

Em 1987 a ONU cria a Comissão Mundial (Comissão Brundtland) com o objetivo de reexaminar os principais problemas do desenvolvimento e do ambiente, garantindo um progresso sustentável para a população mundial.

No Brasil, em 1991, o governo lança a portaria 678 (MEC 14/05/91) que determina que os sistemas de ensino - em todos os níveis, modalidades e instâncias contemplem, nos currículos, temas e conteú- dos de Educação Ambiental. No mesmo ano, em agosto, são publicadas, pelo Ibama, as orientações básicas da Educação Ambiental. É o primeiro pronunciamento formal do governo sob as recomendações de Tbilisi.

Em 1992 realiza-se a conferência da ONU sobre o Meio Ambiente e Desenvolvimento (Unced) ou, mais conhecida, como RIO-92 ou ECO-92. O mais importante do encontro foi o reconhecimento de que o atual modelo de desenvolvimento é insustentável. Assim, é necessário buscar um novo desenvolvimento que seja sustentável. Cria-se a Agenda 21, um plano de ação a ser utilizado pelos municípios, estados e governos.

Finalmente, é realizada a I Conferência Nacional de Educação Ambiental, envolvendo a Rede Brasileira de Educação Ambiental (REBEA). O MEC (Ministério da Educação) divulga, na oportunidade, os novos Parâmetros Curriculares Nacionais, onde a dimensão ambiental é colocada como tema transversal no ensino fundamental. Apesar disso, a Educação Ambiental não é novidade no Brasil. Ela já era "presente", embora com outros nomes: o Decreto Legislativo Federal, número 03 (13/02/1948), por exemplo, aprovava a Convenção para a Proteção da Flora, Fauna e Belezas Cênicas Naturais dos Países da América, com uma característica ecológica. Em 1965 foi aprovado o Novo Código Florestal (lei federal número 4.771) e a Educação Ambiental aparece como Educação Florestal. Em 1988 a Educação Ambiental é citada em uma constituição brasileira (inciso VI, artigo 225, capítulo VI do Meio Ambiente), entretanto, não aparece nenhuma dimensão pedagógica, pois é citada no capítulo de Meio Ambiente.

Segundo Pedrini (1998, p.37) a “Educação Ambiental está sendo prioritariamente realizada nos órgãos ambientais, embora existam esforços discursivos na área educacional e da ciência e tecnologia". Esta afirmativa é bem real: os órgãos responsáveis pela política de educação 
ambiental ainda não incorporaram a devida importância da questão em sua prática cotidiana; o pior, ainda, é que o ensino formal sofre de muitas carências acadêmicas, que vão desde formação técnica até infra-estrutura para trabalho de campo (lembrando que educação ambiental se faz dentro e fora de salas de aula). Práticas de educação já são difíceis por sua natureza, exigindo um bom preparo psicológico que, no Brasil, apenas a prática do esquema "tentativa e erro" acabam funcionando, servindo de suporte empírico para a formação de nossos professores de ensino fundamental e médio. A Educação Ambiental não é diferente, apenas exigindo um empenho maior, pois as questões ambientais trazem à tona um conhecimento que solicita pesquisa e estudo, uma vez que a interdisciplinaridade é uma realidade, e não apenas um sonho pedagógico.

A Política Nacional de Meio Ambiente (PNMA), onde a Educação Ambiental é citada, foi instituída, oficialmente, em 1981 (Lei 6.938, de 31 de agosto de 1981). Cria-se, então, o Sistema Nacional do Meio Ambiente (SISNAMA), o Conselho Nacional do Meio Ambiente (CONAMA) e o Cadastro Técnico Federal de Atividades e Instrumentos de Defesa Ambiental. Ainda na década de 80, em 1989, a lei número 7.335 cria o Instituto Brasileiro do Meio Ambiente e dos Recursos Naturais Renováveis (IBAMA). O IBAMA elabora, posteriormente (1994), através do Grupo de Trabalho de educadores da Divisão de Educação Ambiental, o Programa Nacional de Educação Ambiental (PRONEA). Obtêm o apoio do MEC e da UNESCO na operacionalização das diretrizes do PRONEA. Pedrini avalia que o referencial conceitual do PRONEA é a declaração da Conferência de Educação Ambiental de Tbilisi. Em 1999, é promulgada a lei que estabelece a criação da Política Nacional de Educação Ambiental (Lei 9.795, de 27 de abril de 1999).

Nos anos sessenta e setenta, no Brasil, a discussão política sobre educação ambiental praticamente não existia, uma vez que, vivía- mos sobre a forte presença de uma ditadura que inviabilizava o debate. Assim, durante este período, o debate ambientalista mundial se dava entre nós sob o viés do naturalismo, afastado da articulação entre ambientalismo e sociologia. Posteriormente, com a abertura política, o calor do debate de uma nova constituição e a mobilização de diversos movimentos populares, fez com que a educação ambiental fosse ganhando um caráter coletivo, democrático e popular, popularizando, inclusive, o próprio termo.

Na década de 90, o debate sobre a disciplina da educação ambiental ganha um desfecho final com os Parâmetros Curriculares Nacionais - PCN $N^{\underline{s}}$ que terminaram consolidando a posição do Conselho Federal de Educação de 1987 de não constituir a educação ambiental como disciplina específica, tendo adquirido em sua formulação final o caráter de tema transversal, apresentado pelos $P C N^{\sharp} . A$ própria Lei 9.795/99 reafirma esse posicionamento em seu artigo 10 , parágrafo primeiro: 'A educação ambiental não deve ser implantada como disciplina específica no currículo de ensino'. Apesar dessa decisão, o final da década de 90 e o início do novo século reintroduzem a educação ambiental nos currículos escolares, sob novo enfoque, agora compondo uma parte diversificada $e$ flexibilizada do currículo escolar. (CARLOS HIROO SAITO, In: RUSCHEINSKY, 2002, p49).

Em 2002, realiza-se em Joanesburgo, na África do Sul, a conferência da ONU sobre o Meio Ambiente e Desenvolvimento, conhecida como RIO+10. A avaliação geral é que o encontro resulta em um grande fracasso onde se constata que avanços não foram efetivados. 


\section{Encontros ambientais}

Os encontros ambientais e as leis que estabelecem a educação ambiental em nosso país cumprem a função de situar-se no mundo. Porém, não podemos perder de vista que para cada encontro, para cada reunião legal, seja de uma constituição, uma carta de boa intenção, portaria, enfim, qualquer instrumento legal que introduz a educação ambiental, há uma possibilidade de nos iludirmos quanto ao fato de pensarmos a história em uma continuidade com "final feliz" (uma herança do pensamento hegeliano que estabelece uma noção abstrata de um Espírito absoluto, uma essência, uma idéia de liberdade), uma continuidade da tradição do pensamento alemão, do ser na história. Quer dizer, fizemos os encontros, "criamos" a educação ambiental, agora, portanto, é apenas esperarmos $\mathrm{o}$ final dos resultados das premissas dadas! Ora, as ciências sociais não funcionam assim, ela depende da atuação dos indivíduos e não apenas de uma somatória racional do jogo social. Norbert Elias nos fala sobre funções sociais, papéis representativos, lugares que os indivíduos ocupam dentro de redes de atuação, sociedade de indivíduos, enfim, um "funcionalismo social" (no sentido de uma sociologia do conhecimento), ele não está querendo dizer que estas categorias de pensamento, que nos ajudam a entender o mundo social, são estáticas. Ao contrário, elas estão em pleno movimento. A diferença é que na obra de Elias ele está aberto para ver a sociedade da maneira que ela se apresenta, não sem influências sociais sentidas e sendo provocadas pelos indivíduos que interagem, mas acontecendo, sem idealizações de tipos de sociedade e conceitos pré-estabelecidos, forçando a compreensão de fatos sociais à luz de uma formação já dada de pensar.

Elias nos lembra que ninguém planejou a sociedade, pois é a dinâmica entre os indivíduos que determina a formação que as diversas figurações tomam. O momento histórico é absolutamente cego, ninguém sabe efetivamente o rumo que irá tomar, ainda que os cientistas sociais tentem adivinhar. A ação dos indivíduos e dos grupos sociais em um determinado momento histórico é específica do momento, sem que possamos determinar o rumo preciso dos acontecimentos. Os homens não agem, apenas, predeterminados pela razão, trazem elementos emotivos que se fundem em suas práticas sociais, muitas vezes sendo determinantes em alguns momentos. A "sociogênese", os fundamentos das mudanças ocorridas em toda a sociedade, paralelamente, ocorre com a "psicogênese", com as estruturas de personalidade dos indivíduos (a relação se dá em "nós" e não em "eu"). Os encontros ambientais e as leis produzidas são frutos de momentos históricos muito precisos, que envolvem fatos que estão relacionados com o momento em que foram produzidos, com a "maturidade" da humanidade daquele episódio. Analisar cada um seria impossível aqui, pois a tarefa exige fôlego muito maior, porém, podemos observar que é um evento em continuidade, uma transmissão do conhecimento humano compartilhado culturalmente com outros indivíduos. Isto não significa que o processo civilizador se dará em uma "paz absoluta" entre todos os povos da Terra desejável seria - em uma "continuidade positiva" dos encontros e na solução de todos os problemas de utilização dos "bens" naturais. Significa que o conhecimento compartilhado e a cultura herdada destes encontros são uma face do processo civilizador; não um estágio, estado de permanência ou qualquer sinônimo que dê este sentido, mas, uma face, com o sentido de um fato observável de como os indivíduos estão se organizando para tentar solucionar problemas bem concretos e imediatos entre todos os habitantes do planeta. Aliás, habitantes que se reconhecem como pertencentes a uma mesma humanidade, evidência de que o processo civilizador é vivo, atuante.

Há um grau de emotividade produzida pelos homens nos encontros e leis, que faz com que um novo arranjo emocional seja possível, sendo inclusive, um poderoso instrumento metodológico para as educações ambientais. A ação e o pensamento individual na relação 
com os outros homens, tem levado à uma forma de pensamento que é única na história da humanidade, o que faz possível falarmos de "educações ambientais". Os encontros ambientais possuem uma face de continuidade que lentamente incorporam realidades de seu tempo, mas, também, de um tempo passado, de uma natureza perdida, que é comum a toda a humanidade, seja através de uma herança cristã (o mito da natureza intocada), seja através do processo civilizador e da sociedade de corte que institui o estado burguês e os ideais de democracia (apaziguamento da sociedade), ou, mais longinquamente, através de um autocontrole das pulsões agressivas de um tempo em que os homens tiveram que se refugiar nas cavernas para se proteger dos outros animais, de um tempo em que eram caçados; só recentemente os homens aprenderam a dominar a natureza. Os encontros ambientais como vemos, é um fato social novo do processo civilizador que propicia aos homens a oportunidade de se reconhecer enquanto uma única humanidade, lembrando que uma "única" humanidade não significa harmonia ou ausência de conflito. Há uma continuidade que pode ser observada pela riqueza de significados atribuídos às diversas vertentes de "educações ambientais", como uma evidência deste processo.

\section{Educação Ambiental: vertentes}

A prática de Educação Ambiental (formal e não-formal) no Brasil não é acompanhada de perto por nenhum órgão "fiscalizador" ou orientador, apesar da avançada legislação ambiental e dos documentos oficiais. As Redes de Educação Ambiental, o Ibama, o Ministério do Meio Ambiente, as Secretarias Estaduais, as Organizações Não-Governamentais (Greenpeace, WWF-Brasil, Fundação O Boticário, entre outras) possuem trabalhos sérios na área, entretanto, não é possível avaliar com maior cuidado este movimento, uma vez que não há uma integração sistemática, apesar de muitos esforços. Os encontros de educação ambiental existem, certamente, porém, sofrem de um contato maior para a troca de experiência, senão no meio acadêmico, pelo menos em relação ao senso comum. O Ministério da Educação e Desporto (MEC) tem iniciativas para incentivar a educação ambiental no ensino formal, entretanto, são atitudes ainda muito tímidas.

O ensino da chamada educação ambiental ainda está sendo escrito no Brasil por alguns nomes que participam da história da mesma: Marcos Sorrentino, Phillipe Layrargues, Marcos Reigota, Genebaldo Freire Dias, Héctor Leis, Aloísio Ruscheinsky, Lúcia da Costa Ferreira, Eduardo Viola, Pedro Jacobi, José de Augusto Pádua, Fábio Cascino, Carlos Eduardo Matheus, Maria Guiomar Tomazello, entre outros. São pessoas que, além da prática acadêmica, estão envolvidas, de alguma maneira, com a prática ambientalista ou acadêmica; ou, com o "fazer" educação ambiental. Além destes nomes uma série de "ilustres desconhecidos" fazem também a chamada educação ambiental.

Philippe Pomier Layargues, no $\mathrm{I}^{-}$ Simpósio Sul Brasileiro de Educação Ambiental, II $^{\circ}$ Simpósio Gaúcho de Educação Ambiental e XIV Semana Alto Uruguai do Meio Ambiente, realizado em setembro de 2002, em Erechim, no Rio Grande do Sul, apresentou o artigo intitulado Educação no Processo da Gestão Ambiental: criando vontades políticas, promovendo mudança (ERECHIM, 2002, p127). Neste o autor faz um balanço da Educação Ambiental, com suas principais vertentes. O primeiro problema levantado por Layargues é que o termo Educação Ambiental é entendido no singular. Para ele deveria ser entendido no plural, ou seja, deveríamos falar de Educações Ambientais, uma vez que existem diversos entendimentos sobre o que seja o termo. Existem múltiplas visões sobre a crise ambiental e, conseqüentemente, múltiplas práticas e conceitos pedagógicos, vários interesses se estabelecem em relação à 
natureza, interesses de preservação, conservação, etc., ou seja, o autor reconhece que há um conflito sócio ambiental. Tal conflito produz visões sobre a natureza, que conhecemos como ambientalismo (um fenômeno social).
Layargues classifica as educações ambientais nas seguintes interpretações: filosófica, política, ética, perceptiva e de atitudes políticas. Para facilitar a visão do leitor, vamos apresentar as classificações em forma de quadro.

PHILIPPE POMIER LAYARGUES

\begin{tabular}{|c|c|c|}
\hline FILOSÓFICA & $\begin{array}{c}\text { ECOCENTRISMO } \\
\text { Natureza como centro do universo. } \\
\text { ANTROPOCENTRISMO } \\
\text { Homem como centro do universo. }\end{array}$ & $\begin{array}{l}\text { ANTROPOCENTRISMO ECOLÓGICO } \\
\text { Fusão das duas visões. } \\
\text { Catástrofe ecológica. }\end{array}$ \\
\hline & $\begin{array}{l}\text { ANTROPOCENTRISMO } \\
\text { ECOLÓGICO }\end{array}$ & $\begin{array}{l}\text { ECOLOGIA PROFUNDA } \\
\text { Ser humano como natureza consciente de si, } \\
\text { sendo a cultura a continuidade de uma projeção } \\
\text { evolutiva da natureza. } \\
\text { ECOLOGIA SUPERFICIAL } \\
\text { Proteção da natureza e da qualidade de vida } \\
\text { humana, (Natureza como fonte de recurso e não } \\
\text { como valor intrínseco). }\end{array}$ \\
\hline POLÍTICA & $\begin{array}{l}\text { ECO-SOCIALISMO } \\
\text { ECO-ANARQUISMO } \\
\text { ECO-CAPITALISMO } \\
\text { ECO-AUTORITARISMO }\end{array}$ & $\begin{array}{l}\text { ECO-SOCIALISMO } \\
\text { O problema está no modo de produção capitalista } \\
\text { e na exploração do capital. } \\
\text { ECO-ANARQUISMO } \\
\text { Os problemas ambientais estão na hierarquia e na } \\
\text { dominação. } \\
\text { ECO-CAPITALISMO } \\
\text { Privatização e mercantilização da natureza. } \\
\text { ECO-AUTORITARISMO } \\
\text { Intervenção do Estado; medidas drásticas onde a } \\
\text { democracia é um entrave. }\end{array}$ \\
\hline ÉTICA & $\begin{array}{l}\text { Héctor Leis } \\
\text { Analisa a relação homem / sociedade e } \\
\text { homem / natureza. } \\
\text { ALFA } \\
\text { BETA } \\
\text { GAMMA } \\
\text { OMEGA }\end{array}$ & $\begin{array}{l}\text { ALFA } \\
\text { Individualista e antropocêntrica; proteger a } \\
\text { natureza para proteger o homem. } \\
\text { BETA } \\
\text { Comunitária e antropocêntrica; proteger o } \\
\text { ambiente e as injustiças sociais. } \\
\text { GAMMA } \\
\text { Individualista e biocêntrica; proteger mais a } \\
\text { natureza do que os homens. } \\
\text { OMEGA } \\
\text { Comunitária e biocêntrica; manifesta nos textos } \\
\text { sagrados. }\end{array}$ \\
\hline PERCEPTIVA & $\begin{array}{c}\text { FUNDAMENTALISTAS } \\
\text { ALTERNATIVOS } \\
\text { NEOMALTHUSIANOS } \\
\text { ZERISTAS } \\
\text { VERDES } \\
\text { ECO-TECNICISTAS }\end{array}$ & $\begin{array}{l}\text { FUNDAMENTALISTAS } \\
\text { Defendem o eco-centrismo. } \\
\text { ALTERNATIVOS } \\
\text { Combatem a cultura ocidental. } \\
\text { NEOMALTHUSIANOS } \\
\text { Combatem o crescimento populacional. } \\
\text { ZERISTAS } \\
\text { Crescimento "zero". }\end{array}$ \\
\hline
\end{tabular}




\begin{tabular}{|c|c|c|}
\hline & MARXISTAS & $\begin{array}{l}\text { VERDES } \\
\text { Combatem o capitalismo e o socialismo. } \\
\text { Inspiração anarquista. } \\
\text { ECO-TECNICISTAS } \\
\text { Otimismo tecnológico. } \\
\text { MARXISTAS } \\
\text { Eco-socilaismo. }\end{array}$ \\
\hline $\begin{array}{l}\text { ATITUDES } \\
\text { POLÍTICAS }\end{array}$ & $\begin{array}{l}\text { EXPONENCIALISMO } \\
\text { COMPATIBILISMO } \\
\text { PRESERVACIONISMO } \\
\text { CONSERVACIONISMO } \\
\text { AMBIENTALISMO } \\
\text { ECOLOGISMO }\end{array}$ & $\begin{array}{l}\text { EXPONENCIALISMO } \\
\text { Crescimento ilimitado com capacidade física } \\
\text { limitada; a poluição como um mal necessário. } \\
\text { COMPATIBILISMO } \\
\text { Desenvolvimento com proteção ambiental. } \\
\text { PRESERVACIONISMO } \\
\text { Isolar a natureza do ser humano e protegê-la. } \\
\text { CONSERVACIONISMO } \\
\text { Uso racional dos recursos naturais. } \\
\text { AMBIENTALISMO } \\
\text { Menos reflexiva e mais ativa, aproxima-se do } \\
\text { compatibilismo. } \\
\text { ECOLOGISMO } \\
\text { Reflete sobre a crise ambiental; possui um forte } \\
\text { conteúdo utópico. }\end{array}$ \\
\hline
\end{tabular}

Uma outra classificação existente, referente ao movimento ambientalista, é a de Eduardo Viola. O autor faz um estudo da expansão da cultura ambientalista através da história do Brasil. Assim, divide o ambientalismo em: uma fase fundacional (1971 - 1986: bissetorialista, ou seja, entidades ecológicas e órgãos estatais); uma fase de consolidação (1988: multissetorial, parlamento, movimento feminino, movimento negro, questão indígena, movimento religioso, etc) e, por fim, uma fase pós-Rio 92 (1992: transetorial, surgimento das redes temáticas de meio ambiente).

\section{EDUARDO VIOLA}

\begin{tabular}{|c|c|l|}
\hline $\begin{array}{c}\text { FASE } \\
\text { FUNDACIONAL }\end{array}$ & $1971-1986$ & $\begin{array}{l}\text { Bissetorialismo: } \\
\text { entidades ecológicas e órgãos } \\
\text { estatais. }\end{array}$ \\
\hline $\begin{array}{c}\text { FASE } \\
\text { DE } \\
\text { CONSOLIDAÇÃO }\end{array}$ & 1988 & $\begin{array}{l}\text { Multissetorialismo: } \\
\text { parlamento, movimento feminino, } \\
\text { negro, indígena, religioso, etc. }\end{array}$ \\
\hline $\begin{array}{c}\text { FASE } \\
\text { PÓS-RIO 92 }\end{array}$ & 1992 & $\begin{array}{l}\text { Transetorialismo: } \\
\text { surgimento das redes temáticas de } \\
\text { meio ambiente. }\end{array}$ \\
\hline
\end{tabular}

O professor Antônio Carlos Robert Moraes identifica três posturas que envolvem a comunidade cientifica que se dedica à problemática ambiental: o naturalismo, o tecnicismo e o romantismo.

O naturalismo expressa uma postura filosófica perante o mundo, a história, a relação homem-natureza, que perde totalmente a sua dimensão social. Análises que não falam de sociedade, mas apenas de 'ação antrópica' ou uma visão holística.

A postura naturalista é uma revivência que a temática ambiental trazpara as ciências 
humanas contemporâneas, pois havia em grande parte sido enterrada - ao longo deste século - com a crise do positivismo clássico nos vários campos de conhecimento (MORAES, 1997,p53).

O tecnicismo dilui as implicações políticas do manejo ambiental, transformando a problemática ambiental em apenas 'soluções técnicas'. Quer dizer, os conflitos políticos são colocados em segundo plano, em nome de uma legitimação centrada na técnica.

O romantismo, diferente da técnica, peca pelo excesso de politização, entretanto, geralmente, com fundamentação frágil ou inadequada. Parte-se do pressuposto ingênuo - de que a política é o campo do bem comum e da vontade. Manifesta-se, por exemplo, no preservacionismo radical, o que chamaríamos do discurso 'verde pelo verde'. Segundo Antônio Carlos este radicalismo pode colocar a natureza como um valor maior que o homem, tornando-se assim um discurso antihumanista. Naturalismo, tecnicismo e romantismo:

Não se tratam apenas de idéias $e$ concepções, mas de idéias que se materializam em projetos, em estruturas burocráticas, em encaminhamentos de investigações, em programas de pesquisas, em financiamentose, mesmo, em políticas públicas para o setor. (MORAES, 1997, p.55)

\section{ANTÔNIO CARLOS ROBERT MORAES}

\begin{tabular}{|c|l|}
\hline NATURALISMO & $\begin{array}{l}\text { Relação homem-natureza. Análises que não falam de sociedade, mas apenas de } \\
\text { 'ação antrópica' ou de uma visão holística. }\end{array}$ \\
\hline TECNICISMO & $\begin{array}{l}\text { Conflitos políticos são colocados em segundo plano. Legitimação centrada na } \\
\text { técnica. }\end{array}$ \\
\hline ROMANTISMO & $\begin{array}{l}\text { Excesso de politização. Parte-se do pressuposto - ingênuo - de que a política é o } \\
\text { campo do bem comum e da vontade. Manifesta-se, por exemplo, no } \\
\text { preservacionismo radical ('verde pelo verde'). }\end{array}$ \\
\hline
\end{tabular}

O professor Marcos Sorrentino divide a educação ambiental em quatro vertentes: conservacionista (que estimula a reflexão sobre causas e conseqüências da degradação ambiental); educação ao ar livre (naturalistas, escoteiros, espeleologistas, caminhadas, montanhismo, acampamentos, esporte, lazer); gestão ambiental (como gerir o meio; embates sobre a poluição) e economia ecológica (ecodesenvolvimento de Ignacy Sachs; movimentos sociais, $\mathrm{ONG}^{\mathrm{s}}$, associações ambientalistas, etc) (BRASÍLIA/ IBAMA, 2000, p. 108/109). Para Sauvé, citado por Layargues, há uma complementação entre as 'educações ambientais', podendo ser: educação sobre o meio ambiente (o meio ambiente como objeto de estudo); educação no meio ambiente (o meio ambiente como aprendizado); e, educação para o meio ambiente (o meio ambiente como meta). Ainda, o mesmo autor, estabelece vertentes da relação entre o humano e o ambiente, assim, a educação ambiental poderia se dá nas seguintes perspectivas: ambiental (centrada no ambiente biofísico); educativa (centrada no indivíduo ou grupo social) e pedagógica (centrada no processo educativo). 
MARCOS SORRENTINO

\begin{tabular}{|c|l|}
\hline CONSERVACIONISTA & $\begin{array}{l}\text { Estimula a reflexão sobre causas e conseqüências da } \\
\text { degradação ambiental. }\end{array}$ \\
\hline EDUCAÇÃO AO AR LIVRE & $\begin{array}{l}\text { Naturalistas, escoteiros, espeleologistas, caminhadas, } \\
\text { montanhismo, acampamentos, esporte, lazer. }\end{array}$ \\
\hline GESTÃO AMBIENTAL & Como gerir o meio; embates sobre a poluição. \\
\hline ECONOMIA ECOLÓGICA & $\begin{array}{l}\text { Ecodesenvolvimento de Ignacy Sachs; movimentos } \\
\text { sociais, ONG }{ }^{\underline{s}}, \text { associações ambientalistas, etc. }\end{array}$ \\
\hline
\end{tabular}

Outra vertente que poderíamos incorporar como interpretativa das questões ambientais e que se torna, a nosso ver, parte do processo de assimilação de práticas pedagógicas com vários desdobramentos, é a interpretação de Marcos Reigota. O autor trabalha na linha das representações sociais da ecologia. Entende a mesma, no mundo contemporâneo globalizado, como uma filosofia de um movimento social cuja concepção passa por princípios históricos em sua construção.

\section{As representações sociais da ecologia} têm mostrado que se entende a ecologia, como um pensamento homogêneo, com diferentes interpretações, porém com um denominador comum, sem antagonismos $e$ conflitos internos. A idéia predominante é a de que ecologia é sinônimo de natureza, e que o ecologismo procura preservá-la. (REIGOTA, 2002, p34)

Marcos Reigota defende a idéia de que o pensamento ecologista está em construção, expondo disputas, formações teóricas, ideológicas, fragilidade e força de argumentação. Divide o mesmo em três vertentes: "ecologia global", "alarmista" e "técnica-administrativa". A "ecologia global" tem sua origem nas conseqüências do movimento de 68, em Paris, gerando um questionamento radical das sociedades de vários países: Alemanha, Bélgica, Brasil, EUA, França, etc. As bandeiras levantadas por este movimento ecologista (também conhecido como radical) eram a do pacifismo e da oposição às armas nucleares, lembrando que a tensão de poder que a Europa vivia estava entre o fim da Segunda Grande Guerra
Mundial (1945) e o advento da Guerra Fria, o que tornava o continente europeu um alvo real. De qualquer maneira, o movimento contribuiu para levantar a questão de uma mesma humanidade afetada pelo poderio militar nuclear, ainda que isto fosse distante para nós brasileiros, que só entenderíamos os perigos nucleares após a irresponsabilidade das autoridades no caso do césio, em Goiás.

A vertente "alarmista" está relacionada às repercussões do documento do Clube de Roma (1968), colocando a questão, conhecida, dos limites do desenvolvimento da humanidade e do desperdício das sociedades, como desdobramento do modelo de desenvolvimento adotado. A vertente "técnicaadministrativa" surgiu das conseqüências do impacto do Clube de Roma e teve suas referências conhecidas na Conferência de Estocolmo (1972), onde os padrões de utilização dos recursos naturais do planeta devem ser preservados "em benefício das gerações atuais e futuras, mediante um cuidadoso planejamento ou administração adequados" (DECLARAÇÃO DA ONU, princípio 2, 1972).

Além destas vertentes, Reigota enumera mais quatro visões que fizeram parte dos debates ambientais, nos anos 90, ligados à produção teórica dos países do Sul (nova designação pós-Guerra Fria: Norte / Sul; ricos / pobres) e que, como visualizamos, perpassam várias práticas pedagógicas de educação ambiental. São elas: 1) conformista; conservacionista e new age; 2) científico e econômica; 3) radical; 4) catastrófica. 


\section{MARCOS REIGOTA}

1) CONFORMISTA; CONSERVACIONISTA E NEW AGE;

\begin{tabular}{|c|l|}
\hline CONFORMISTA & $\begin{array}{l}\text { Segue as diretrizes oficiais; não alteram o status quo } \\
\text { econômico, político e cultural vigente; }\end{array}$ \\
\hline CONSERVACIONISTA & Preservar a natureza, não politizando a questão. \\
\hline NEW AGE & $\begin{array}{l}\text { "Sacraliza a natureza e mediatiza todas as relações } \\
\text { sociais com ela, através de argumentos metafísicos” } \\
\text { (REIGOTA, 2002, p.39). O problema ambiental } \\
\text { passa por uma questão energética pessoal; por } \\
\text { princípio apolítica. }\end{array}$ \\
\hline
\end{tabular}

2) CIENTÍFICO E ECONÔMICA;

\begin{tabular}{|c|l|}
\hline CIENTÍFICO & Incorpora a noção de desenvolvimento sustentável. \\
\hline ECONÔMICA & $\begin{array}{l}\text { Enfoque reformista, conciliador e contemporâneo ao } \\
\text { modelo capitalista. }\end{array}$ \\
\hline
\end{tabular}

3) RADICAL;

\begin{tabular}{|l|l|}
\hline RADICAL & $\begin{array}{l}\text { Novas relações entre cultura, sociedade e natureza; } \\
\text { Necessidade de novas alianças éticas para a } \\
\text { sobrevivência das formas de vida e cultura. }\end{array}$ \\
\hline
\end{tabular}

4) CATASTRÓFICA;

\begin{tabular}{|l|l|}
\hline CATASTRÓFICA & $\begin{array}{l}\text { Não haverá nenhum futuro diante do aparato militar } \\
\text { do planeta. }\end{array}$ \\
\hline
\end{tabular}

O que todas estas interpretações representadas tem em comum, segundo Reigota, é o fato do princípio ecológico da interdependência de todos os elementos e relações dos seres vivos, além da relação destes com o meio social.

Como vemos, o "fazer" educação ambiental tem uma variedade de posturas e compromissos ideológicos estabelecidos por estas vertentes, ora comprometidas com questões econômicas, éticas, comportamentais, no sentido de "policiadas ideologicamente", etc, enfim, 'de quê' educação ambiental fala-se? O que é educar ambientalmente? Quem educa? o que se quer educar? A lista de perguntas pode ser infinita, dada a variedade de visões ambientais.

As perspectivas sobre educação ambiental se multiplicam tanto quanto as visões e representações que os homens fazem sobre si mesmos e sobre a natureza não humana. Acreditamos que as perspectivas adotadas para quaisquer práticas de educação ambiental carregam processos configuracionais em que os indivíduos estejam interrelacionados, ou seja, a representação que o indivíduo aprende sobre a natureza - humana e não humana - é herdada de outros indivíduos, bem como compartilhada culturalmente entre eles através de um processo social.

Ao falarmos de meio ambiente, natureza, ambientalismo, ecologismo, etc, ou seja, em uma série de definições relacionadas às questões ambientais, será que todos nós temos o mesmo entendimento daquilo que está sendo proposto? Será que todos nós entendemos, por exemplo, o termo natureza da mesma forma? Entendemos educação ambiental como um 'conteúdo programático'? $\mathrm{Na} I^{\underline{a}}$ Conferência Intergovernamental sobre Educação Ambiental, em Tbilisi (Geórgia, exURSS), tida como um marco conceitual, a Educação Ambiental:

Foi definida como uma dimensão dada ao conteúdo e à prática da Educação, orientada para a solução dos problemas concretos do meio ambiente, através de enfoques interdisciplinares e de uma participação ativa e responsável de cada 
indivíduo e da coletividade (LEÃO \& SILVA, 2001,p13)

Em última instância, na nossa visão, o que dá ênfase e dimensão de conteúdo e prática à Educação Ambiental são os indivíduos. Colocado em um determinado grupo, ao nascer, o indivíduo será iniciado no mundo com uma determinada visão de natureza ou meio ambiente, de acordo com o que o grupo entende por estes termos. Um trabalho pedagógico de educação ambiental tem de levar em conta estas diversas visões que os indivíduos trazem culturalmente com eles. $\mathrm{O}$ ponto a ser destacado, parece, é o de possibilitar que estas interpretações sejam conhecidas por todos aqueles que se dispuserem a estudar ou realizar um trabalho de educação ambiental, ainda que não se saiba exatamente aonde se chegará.

\section{BIBLIOGRAFIA}

ANAIS DO I SIMPÓSIO SUL BRASILEIRO DE EDUCAÇÃO AMBIENTAL; II SIMPÓSIO GAÚCHO DE EDUCAÇÃO AMBIENTAL; XIV ${ }^{\text {a }}$ SEMANA ALTO URUGUAI DO MEIO AMBIENTE / Diversidade na Educação Ambiental - Olhares e Cores / Organização Sônia Beatriz Balvedi Zakrzevski, Alice Teresa Valduga, Ivano Alessandro Devilla. Erechim / RS: 09 a 12 de setembro de 2002. Erchim: EdiFapes, 2002.

BRASIL. Ministério da Educação. Secretaria de Educação Média e Tecnológica. Parâmetros curriculares nacionais: ensino médio: bases legais / Ministério da Educação. - Brasília: Ministério da Educação / secretaria de Educação Média e Tecnológica, 1999.

CARTA DO RIO SOBRE DESENVOLVIMENTO E MEIO AMBIENTE (RIO-92 OU ECO-92).

CONAMA - Diário Oficial da União de 18/03/1988, seção I, página 4.563. CONSTITUIÇÃO BRASILEIRA(1988).

DECLARAÇÃO UNIVERSAL DOS DIREITOS HUMANOS (ONU, 1948).
DECLARAÇÃO DA ONU SOBRE O M E I O A M B I E N T E H U M A N O (ESTOCOLMO, 1972).

DECLARAÇÃO DA CONFERÊNCIADE TBILISI (TBILISI, 1977).

DIAS, Genebaldo Freire. Educação Ambiental: Princípios e Práticas. 6. ed. revista e ampliada. São Paulo: Gaia, 2000.

DIEGUES, Antonio Carlos Sant'ana.

O Mito Moderno da Natureza Intocada. Núcleo de Apoio à Pesquisa Sobre Populações Humanas e Áreas Úmidas Brasileiras / USP. São Paulo: Hucitec, 2001.

ELIAS, Norbert. O Processo Civilizador. Volume I: Uma História dos Costumes. Rio de Janeiro, Zahar, 2v, 1994. A Sociedade dos Indivíduos.

Rio de Janeiro: Zahar, 1994.

A Condição Humana.

Lisboa: Difusão Editorial, 1991.

Envolvimento e Distanciamento - Estudos sobre sociologia do conhecimento. Lisboa: Dom Quixote, 1997. La Sociedad Cortesana.

Fundo de Cultura Econômica. México, 1996.

GEBARA, Ademir. Norbert Elias e a Teoria do Processo Civilizador: contribuição para a Análise e a Pesquisa no Campo do Lazer. In: BRUHNS, Heloisa Turín (Org.). Temas sobre Lazer. Campinas: Autores Associados, 2000 .

Anotações Para a Teoria do Processo Civilizador: Proposições para a História da Educação. Comunicações. Piracicaba, SP. v.2, 1998.

LEÃO, Ana Lúcia Carneiro \& SILVA, Lúcia Maria Alves. Fazendo Educação Ambiental. 5. ed. revista e atualizada. Recife: Companhia Pernambucana do Meio Ambiente (CPRH), 2001.

Ministério do Meio Ambiente. Coleção: Água, Meio Ambiente e Cidadania. MORAES, Antônio Carlos R. Meio Ambiente e Ciências Humanas. 2. ed. São Paulo: Hucitec. 1997.

PEDRINI, Alexandre de Gusmão (Org.). Educação Ambiental: Reflexões e Práticas 